\title{
Multiple malignant primary neoplasms in patients with gastric neoplasms in the health district of León
}

\author{
A. Muela Molinero, F. Jorquera Plaza' ${ }^{1}$ T. Ribas Ariño ${ }^{2}$, R. Malagón Rojo ${ }^{3}$, V. Espinel Díez \\ B. Ballesteros del Río, J. L. Olcoz Goñi ${ }^{1}$ and J. A. Santos Calderón \\ Services of Internal Medicine, ${ }^{\prime}$ Gastroenterology and ${ }^{2}$ Pathology. ${ }^{3}$ Tumor Registry. León Hospital. León, Spain
}

\begin{abstract}
Objectives: we analyzed the characteristics of patients with gastric tumors diagnosed with multiple malignant primary neoplasm (MMPN) in the Health District of León.

Material and methods: using the information in the Tumor Registry at León Hospital patients selected were those with gastric neoplasms diagnosed between 1993 and 2002. A follow-up was performed until December 31, 2004, and the characteristics of patients diagnosed with a second neoplasm were analyzed.

Results: MMPN prevalence was 1,96\%; 56\% of patients had a history of cancer in first-degree relatives. The most frequent second neoplasms were digestive (26\%) and urologic (21\%); $87 \%$ of patients were diagnosed with a second neoplasm within the first two years. No significative differences in survival were observed among patients with synchronous or metachronous MMPN.

Conclusions: MMPN in patients with gastric neoplasms is a relevant problem. While external carcinogenic agents could act as promoters in the development of second neoplasms, these patients seem to have a genetic background favoring the development of MMPN. Secondary prevention is the best measure to avoid MMPN development.
\end{abstract}

Key words: Multiple neoplasms. Synchronous. Metachronous. Prostate. Survival. Prognosis. Oncology.

Muela Molinero A, Jorquera Plaza F, Ribas Ariño T, Malagón Rojo R, Espinel Díez V, Ballesteros del Río B, Olcoz Goñi JL, Santos Calderón JA. Multiple malignant primary neoplasms in patients with gastric neoplasms in the health district of León. Rev Esp Enferm Dig 2006; 98: 907-916.

Recibido: $15-07-05$

Aceptado: 02-03-06.

Correspondencia: Alberto Muela Molinero. C/ Abad de Santillán, 15, $2^{\circ}$ A. 24008 León. e-mail: albmuela@yahoo.es

\section{INTRODUCTION}

The first author who used the concept of multiple malignant primary neoplasm (MMPN) was Bilroth in 1889 (1). The presence of two or more neoplasms in the same patient, which was initially considered a curiosity of nature, is nevertheless an increasingly frequent finding of great importance, and has been considered one of the most frequent late complications in oncologic patients $(2,3)$.

In fact the National Tumor Registry indicates that the risk of second neoplams in oncologic patients is 1,29 times versus the general population, which means that $3-10 \%$ of oncologic patients will develop a second neoplasm in their lifetimes (4).

In patients with a gastric neoplasm there is also an increased risk of second tumor, mainly during the first year after the diagnosis of the index neoplasm, with an important decrease in survival (5).

Nevertheless, few studies exist of MMPN in patients with gastric cancer, in most instances with small numbers of patients, and occasionally with contradictory information, which makes knowledge on this condition a difficult task in this patient subgroup.

The aim of the present study is to describe the characteristics of patients with gastric neoplasms who were diagnosed with MMPN in the health area of León (Spain) during the first decade of Tumor Registry operation in our hospital, as well as to analyze the impact on survival in these patients, indicating those variables that should have prognostic value.

\section{PATIENTS AND METHODS}

The Tumor Registry at León Hospital gathers information on all incidental cases occurred in the health area of León from 1993 on; this area has a population of 366,910 
inhabitants, of whom 331,635 are attended by Servicio de Salud de Castilla y León (SACYL). A retrospective study was performed in which all patients diagnosed with gastric neoplasm by SACYL between 1993 and 2002 were included. The Registry's quality indicators at that time are comparable to those observed in registries in other countries (6), with the percentage of cases with histological monitoring being $95,56 \%$.

We selected all those patients with gastric neoplasms that were diagnosed with a second neoplasm during follow-up, which was completed on December 31, 2004. We excluded all patients whose seconds neoplasms were skin baso/spino-cellular tumors, as well as those diagnosed with some malignancy before the study period. Warren and Gates criteria were used (7), according to which: a) both neoplasms had to be different and separated by healthy tissue; b) both neoplasms had to be histologically different; and c) the possibility of metastasis must be excluded. Tumors were considered synchronous when diagnosed in a period shorter than or equal to six months, and metachronous if the interval to diagnosis was longer than six months.

The following variables were included: age, alcohol consumption (in grams/day), tobacco use (in packs of cigarettes/year), family history of cancer in first-degree relatives, life style (urban or rural), date of diagnosis, location and histological type (according to the IDC-9 classification), stage and treatment received for each neoplasm, time interval between neoplasms, and the cause and date of death, if appropriate. Date of diagnosis was defined as the date when a histological report confirmed the diagnosis with cancer. Likewise, the place of residency was considered urban when the number of inhabitants was higher than 10,000 and rural when the above-mentioned number was lower. To analyze the stage of each neoplasm a functional classification was used with three stages: local extension, node involvement, and metastasis. As for treatment, we noted if the patient had received surgery, chemotherapy, radiotherapy, or support therapy only.

For follow-up patient records were reviewed, as were all entries in the Tumor Registry. It Patients or their direct relatives were contacted to rule out patient admission or death in other centers or patient demise in their homes.

The statistical analysis was performed using SPSS v11.0. Results for quantitative variables are expressed as median or mean values \pm standard deviation. For qualitative variable comparisons between groups we used $\chi^{2}$ or Fisher's exact test when necessary, and for quantitative variables we used Student's T-test. Significance was considered for $\mathrm{p}<0,05$. To estimate survival we used the Kaplan-Meier method, and for survival curve comparisons we used logarithmic ranges. Later a multivariate analysis was performed using Cox's regression, and we considered only significant variables, with colinearity being excluded.

\section{RESULTS}

\section{Characteristics of patients with MMPN}

During the period between 1993 and 2002, 1,170 patients with gastric tumors were diagnosed in the health area of León, of which $23(1,96 \%)$ developed an MMPN during the study period. Of these, 12 patients $(52,2 \%)$ had a metachronous neoplasm, and $11(47,8 \%)$ synchronous neoplasms. Crude incidence was 1,44 cases/100,000 inhabitants and year. Cumulative adjusted incidence was 0,55 cases $/ 100,000$ inhabitants and year. Cumulative mean incidence was 3,97 cases/1000 patients and year.

Mean age for these patients was $74 \pm 8$ years (50-92), with a median of 74 years; $78,3 \%$ were males, $69,6 \%$ were smokers or ex-smokers, and 60,9\% drank at least 20 g/day of ethanol. In all 60,9\% of patients came from rural areas, and the rest lived in urban areas; $56,5 \%$ of patients had a family history of cancer in first-degree relatives, with digestive neoplasms such as gastric cancer being most common (Fig. 1). Patients with metachronous MMPNs were 7 years younger at diagnosis with gastric cancer, and had a higher rate of urologic cancers in first-degree relatives versus patients with synchronous MMPNs (Table I).

All gastric neoplasms were adenocarcinomas. In patients with synchronous MMPNs the procedure selected was conservative or palliative versus patients with metachronous MMPNs, who in all cases were treated with potentially curative procedures for their gastric neoplasm (Table II).

\section{Second neoplasms most frequently associated}

Average time between diagnoses of first tumor and second neoplasm was $10 \pm 14$ months $(0-60)$, with a median of 8 months. Considering metachronous cases, the average interval was $20 \pm 14$ months (8-60), and the me-

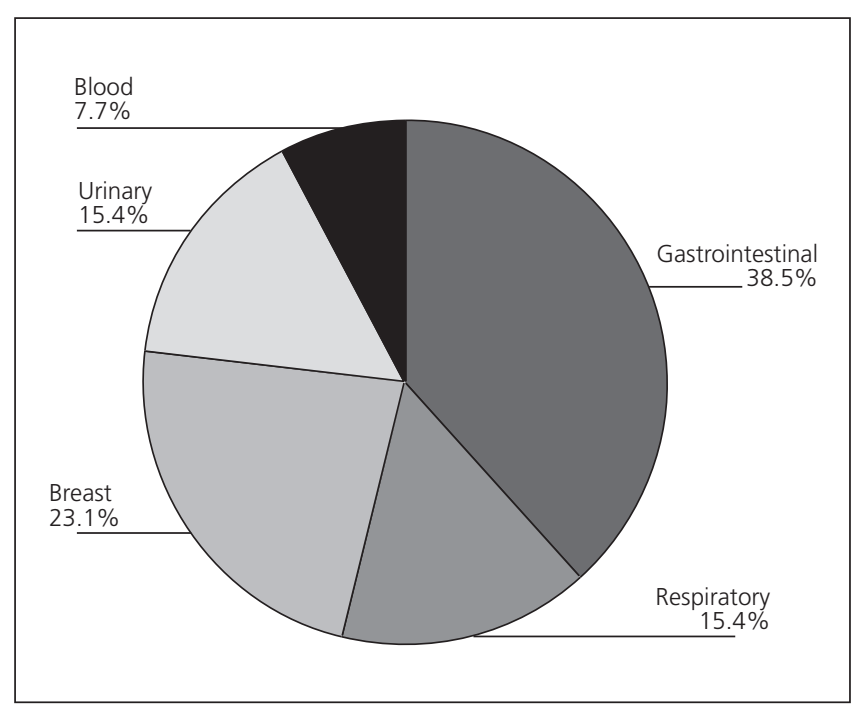

Fig. 1.- Family cancer history.

Antecedentes familiares oncológicos. 
Table I. Epidemiologic characteristics of patients

\begin{tabular}{lccc}
\hline & $\begin{array}{c}\text { Synchronous } \\
\text { MMPN } \\
(n=11)\end{array}$ & $\begin{array}{c}\text { Metachronous } \\
\text { MMPN } \\
(n=12)\end{array}$ & p value \\
\hline Age & $78 \pm 8$ & $70 \pm 7$ & $p<0.05$ \\
Sex (male/female) & $9 / 2$ & $9 / 3$ & pNS \\
Smokers & $7(63.6 \%)$ & $9(75 \%)$ & pNS \\
Alcohol consumption & $7(63.6 \%)$ & $7(58.3 \%)$ & pNS \\
Family history of cancer & $4(36.4 \%)$ & $9(75 \%)$ & $p<0.05$ \\
Urban life & $8(72.7 \%)$ & $6(50 \%)$ & 0.02 \\
\hline
\end{tabular}

Table II. Stage and treatment of each neoplasm

\begin{tabular}{|c|c|c|c|}
\hline & $\begin{array}{c}\text { Synchronous } \\
\text { MMPN } \\
(n=11)\end{array}$ & $\begin{array}{c}\text { Metachronous } \\
\text { MMPN } \\
(n=12)\end{array}$ & $p$ value \\
\hline \multicolumn{4}{|l|}{ Stage of gastric neoplasm } \\
\hline Local & $8(72.7 \%)$ & $9(75 \%)$ & pNS \\
\hline Regional extension/metastases & $3(27.3 \%)$ & $3(25 \%)$ & pNS \\
\hline \multicolumn{4}{|l|}{ Treatment of gastric neoplasm } \\
\hline Surgery & $6(54.5 \%)$ & $12(100 \%)$ & $p<0.05$ \\
\hline Chemotherapy & $1(9.1 \%)$ & $1(8.3 \%)$ & pNS \\
\hline Palliative treatment & $5(45.5)$ & 0 & $p<0.05$ \\
\hline \multicolumn{4}{|l|}{ Stage of second neoplasm } \\
\hline Local & $4(36.4 \%)$ & $6(50 \%)$ & pNS \\
\hline Regional extension/metastases & $7(63.6 \%)$ & $6(50 \%)$ & pNS \\
\hline \multicolumn{4}{|l|}{ Treatment of second neoplasm } \\
\hline Surgery & $4(36.4 \%)$ & $7(58.3 \%)$ & pNS \\
\hline Radiotherapy & 0 & $3(25 \%)$ & pNS \\
\hline Chemotherapy & $2(18.2 \%)$ & $1(8.3 \%)$ & pNS \\
\hline Hormone therapy & 0 & $2(16.7 \%)$ & pNS \\
\hline Palliative treatment & $6(50 \%)$ & $2(16.7)$ & pNS \\
\hline
\end{tabular}

dian was 14 months; in the case of synchronous tumors the average interval between neoplasms was $0 \pm 1$ month (0-3), and the median was 0 months.

Overall, second neoplasms more frequently diagnosed included digestive $(26,1 \%)$ and urologic $(21,7 \%)$ tumors; $54,5 \%$ of synchronous NPMMs were digestive (all of them colorectal tumors); for metachronous MMPNs no clear predominance was observed regarding location (Fig. 2). The most frequent association was gastric adenocarcinoma-colorectal adenocarcinoma $(26,1 \%)$. Table III summarizes the locations of diagnosed second neoplasms.

In all, $60,9 \%$ of patients had been diagnosed with their second neoplasm within 12 months, whereas $87,3 \%$ were diagnosed within 24 months after their diagnosis with a gastric tumor.

Table IV lists stage and treatment for second neoplasms. At the time of diagnosis $21,7 \%$ of patients had regional extension, whereas $4,3 \%$ had developed metastases (to the liver). No significant differences were observed in type of treatment received between synchronous and metachronous MMPNs.

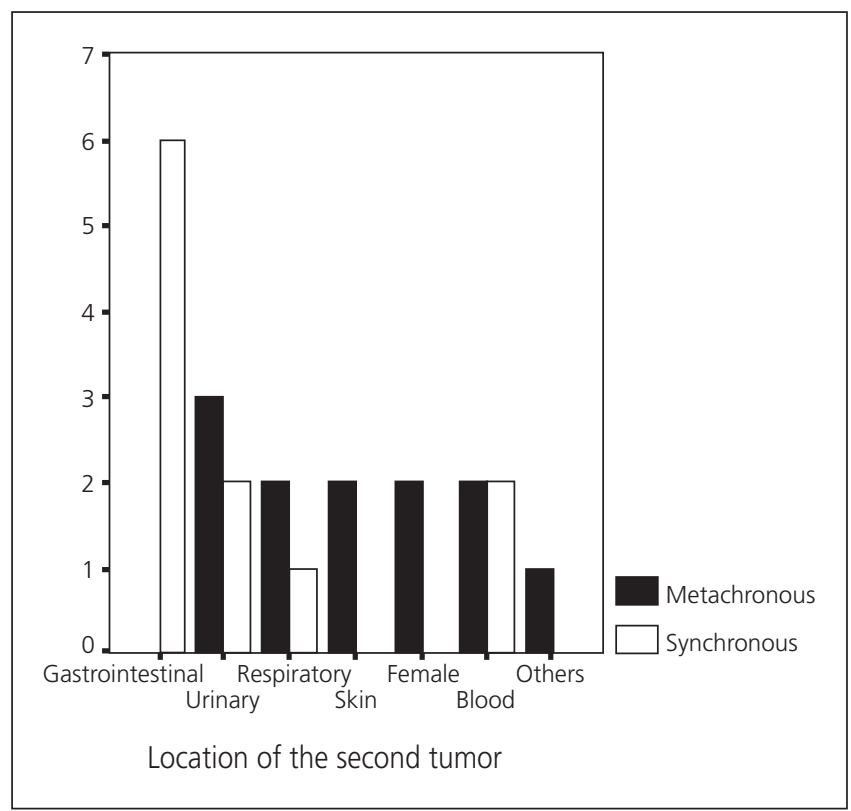

Fig. 2.- Distribution of second neoplasms by location. Distribución de las segundas neoplasias agrupadas por localización.

Table III. Distribution of second neoplasms

\begin{tabular}{lccc}
\hline Location & $\begin{array}{c}\text { Synchronous } \\
\text { MMPN } \\
(n=11)\end{array}$ & $\begin{array}{c}\text { Metachronous } \\
\text { MMPN } \\
(n=12)\end{array}$ & $\begin{array}{c}\text { Total } \\
(n=23)\end{array}$ \\
\hline Colorectal & $5(45.5 \%)$ & 0 & $5(21.7 \%)$ \\
Multiple myeloma & $2(18.2 \%)$ & $1(8.3 \%)$ & $3(13 \%)$ \\
Prostate & 0 & $2(16.7)$ & $2(8.7 \%)$ \\
Lung & $1(9.1 \%)$ & $1(8.3 \%)$ & $2(8.7 \%)$ \\
Renal & $2(18.2 \%)$ & 0 & $2(8.7 \%)$ \\
Skin & 0 & $2(16.7 \%)$ & $2(8.7 \%)$ \\
Breast & 0 & $2(16.7)$ & $2(8.7 \%)$ \\
Liver & $1(9.1 \%)$ & 0 & $1(4.3 \%)$ \\
Larynx & 0 & $1(8.3 \%)$ & $1(4.3 \%)$ \\
Chronic lymphatic leukemia & 0 & $1(8.3 \%)$ & $1(4.3 \%)$ \\
Pharynx & 0 & $1(8.3 \%)$ & $1(4.3 \%)$ \\
Bladder & 0 & $1(8.3 \%)$ & $1(4.3 \%)$ \\
\hline
\end{tabular}

\section{Survival of patients with MMPN}

The survival of patients with metachronous MMPN at the end of the follow-up period was $27,3 \%$, higher than that of patients with synchronous NPMM, which had all died within 24 months of follow-up. Average survival for patients with synchronous MMPN was $9 \pm 3$ months, whereas that for patients with metachronous MMPN was $19 \pm 5$ months. Nevertheless, no significant differences were observed in the Kaplan-Meier analysis, though these came close to statistical significance (Fig. 3).

After a multivariate analysis using Cox's regression the only variable with prognostic value that turned out to be statistically significant was therapeutic abstention in the second neoplasm (RR 3,32 with a 95\% CI of 1,27$8,62 ; \mathrm{p} 0,01)$. In patients selected for palliative treatment the probability of death increased by $332 \%$. 


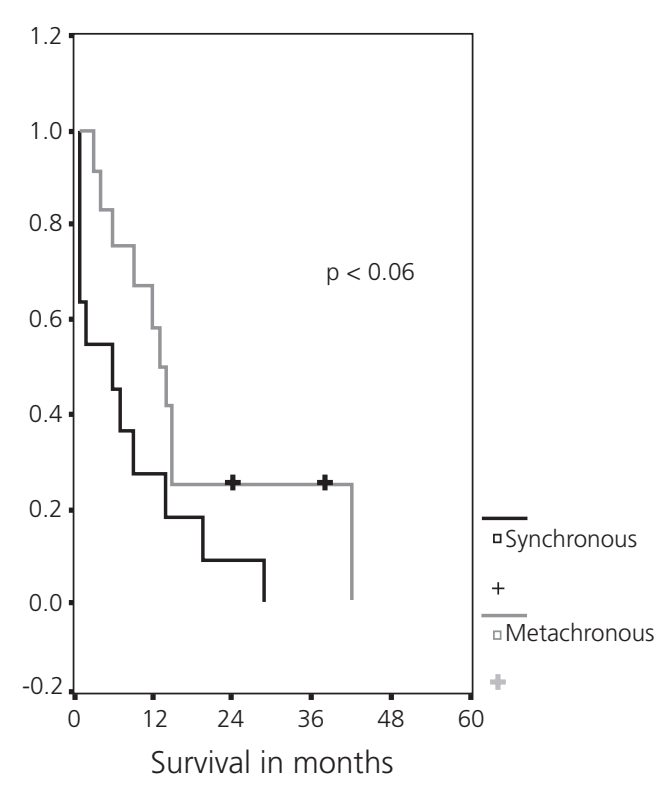

Fig. 3.- Survival of synchronous MMPN vs. metachronous MMPN. Función de supervivencia NPMM sincrónicas vs. metacrónicas.

\section{DISCUSSION}

In the last few decades the incidence of MMPN has increased, which has been related to the improved survival of oncologic patients, the oncogenic effect of chemotherapy and radiotherapy, the increased number of external carcinogenic agents, and a better control of the oncologic population by means of tumor registries (8). Nevertheless, while MMPN has been known for more than one century, little is known about potential risk factors in their etiology, and important controversies exist regarding their incidence. This is largely due to the different criteria chosen to select patients, geographical variability, and patient origin (clinical or autopsy series) $(1,9)$.

In our study the most widely accepted criteria were chosen for the definition of MMPN $(2,9)$, and in spite of the use of indirect information from our Tumor Registry an exhaustive review of clinical records for the patients selected was later performed, and all of them were contacted. The methodology applied in the selection of cases has possibly sacrificed some cases that other works included. Nevertheless this methodology has allowed likewise a more realistic view of the problem, having eliminated those cases diagnosed by radiological conjunction, those with malignant neoplasms before the study period, and second skin baso/spino-cellular neoplasms; we chose to eliminate this type of neoplasms for their high prevalence and virtually nil implication for prognosis, which eliminates a possible bias in data interpretation.

Information on the incidence of MMPN in patients with gastric neoplasms from previous studies is very variable, and ranges between 1,9 and $13,4 \%(10,11)$. These wide differences seem to relate to the criteria chosen to diagnose
MMPN, and the procedence of studies, since in autopsy series the effect is bigger because of latent neoplasms $(1,12)$. The incidence of MMPN in our series is in the lower part of this range of frequencies. Likewise our study shows that $0,39 \%$ of patients diagnosed with gastric neoplasm are then later diagnosed with MMPN every year.

Second neoplasms have been related to age (13). Synchronous MMPN is usually thought to relate to patient intrinsic factors, whereas metachronous MMPN is related to external carcinogens. For this reason patients with synchronous MMPN are younger at diagnosis (14). Mean age in our series is high, similar to previous studies; nevertheless, patients with metachronous MMPN were significantly younger than patients with synchronous MMPN. Follow-up for oncologic patients possibly allows early detection of second neoplasms (15). The high frequencies of alcohol consumption and tobacco smoking were to be expected, as the importance of these agents in the etiology of gastric neoplasms or second neoplasms is well known.

The high prevalence of oncologic family antecedents among patients with MMPN is of great relevance; nevertheless, a great variability is observed in this information due to methodological differences amongst studies (16). In patients with gastric neoplasms who were diagnosed with MMPN, Morita et al. (17) found a prevalence of oncologic family history of $27 \%$, some $15 \%$ higher than that of patients with isolated gastric neoplasms. In our series $56,5 \%$ of patients had antecedents in first-degree relatives, and of these $38,5 \%$ had a positive history of digestive cancer. While we do not know the prevalence of oncologic family antecedents in the population with solitary tumors, this information is higher than that from other series $(16,18,19)$.

The most frequent locations of second neoplasms in patients with gastric cancer diagnosed with MMPN are, in order of frequency: colorectal, uterus, esophagus, breast, and lung (20-22). Our series partly followed this trend, and a high proportion of second tumors were digestive (mainly colorectal) neoplasms. Nevertheless the frequency of second urologic neoplasms turned out to be high $(21,7 \%)$.

The risk of a second neoplasm is independent from the first tumor's stage. All oncologic patients have to be followed because of their potential for tumor relapse or second cancer development. A number of previous studies have demonstrated that an important number of MMPNs are diagnosed late, sometimes decades after the diagnosis of the first tumor $(9,23)$. Nevertheless, in patients with gastric cancer half of second neoplasms are diagnosed during the first year, and the rest during the first five years $(12,24)$. Possibly, the lower survival of patients with gastric neoplasm, as well as the lower frequency of therapies with oncogenic potential (chemo- or radio-therapy) and the milder diagnostic aggressiveness in patients with advanced stages or associated morbidity, explain this information. The information in our series is similar to that reported by previous studies, with $60,9 \%$ of 
MMPNs being diagnosed during the first year and 87,3\% of cases being diagnosed within the first two years.

Controversy exists about the prognosis of patients with synchronous and metachronous MMPN, though a majority of studies indicate that the prognosis of patients with metachronous MMPN is better (25). Nevertheless many limitations exist at the time of assessing these studies. This way, the date of diagnosis with the first tumor is taken for reference, ignoring the disease-free interval to the diagnosis of the metachronous tumor (26). Another problem, as Ikeda et al. (27) suggested, is that patients diagnosed with metachronous MMPN are those whose first neoplasm had a better prognosis. Data from our series allows the statement that survival for these patients do not depend on whether MMPN is synchronous or metachronous, as in the series by Cosme et al. (12). Nevertheless, in our series, the stage of the second neoplasm did not behave as a prognostic variable, in contrast to results obtained by Cosme et al. (12). The only significant variable in the multivariate analysis of our series was therapeutic intent, as a palliative approach was related to a poorer prognosis.

For the prevention of second neoplasms in the digestive tract avoidance of carcinogen consumption or exposure (alcohol and tobacco) is recommended, as is the identification of the population at risk, and patient follow-up, together with a bronchoscopy or gastroscopy study once the index neoplasm is diagnosed (13). Nevertheless, the use of tests to detect second neoplasms early is controversial, since many authors think that there are many patients to control, and few neoplasms are eventually diagnosed $(3,12)$. In fact, in our series, the low number of patients with metachronous neoplasms does not justify the indication of any test in terms of cost/benefit in such a wide oncologic population.

However, our study has important limitations. First, it is a retrospective study using information from our Tumor Registry, where no prospective withdrawal of information has been carried out. In an attempt to make up for this limitation a thorough review of patient records was undertaken, and information was when possible confirmed using a phone survey. Secondly, the number of cases of MMPN is small, and thus important statistical limitations exist.

Finally, in patients with gastric cancer, MMPN represents a relevant concern involving nearly $2 \%$ of cases. The presence of a positive family history for cancer likely plays a predisposing role in these patients. Further studies with a greater number of patients with MMPN and gastric neoplasms are needed. Secondary prevention is the best measure to avoid the development of second neoplasms.

\section{REFERENCES}

1. Demandante CG, Troyer DA, Miles TP. Multiple primary malignant neoplasms: case report and a comprehensive review of the literature. Am J Clin Oncol 2003; 26: 79-83.

2. De la Riva S, Muñoz-Navas M, Sola JJ. Gastric carcinogenesis. Rev Esp Enferm Dig 2004; 96: 265-76.
3. Sankila R, Pukkala E, Teppo L. Risk of subsequent malignant neoplasm among 470.000 cancer patients in Finland 1953-1991. Int J Cancer 1995; 60: 464-70.

4. Rovirosa A, Bellmunt J, López A, et al. Incidencia de segundas neoplasias en el cáncer de laringe avazado. Impacto sobre la supervivencia. Med Clin (Barc) 1994; 102: 121-4.

5. Lundegardh G, Hansson LE, Nyren O, Adami HO, Krusemo UB. The risk of gastrointestinal and other primary malignant diseases following gastric cancer. Acta Oncologica 1991; 30: 1-6.

6. Parkin DM, Whelan SL, Ferlay J, Raymond L, Young J. Cancer incidence in five continents (vol. VII). Lyon: IARC Scientific Publications; 1997. p. 143.

7. Warren S, Gates O. Multiple primary malignant tumors. A survey of the literature and statistical study. Am J Cancer 1932; 16: 1358-64.

8. Nagasawa S, Onda M, Sasajima K, Tabuko K, Miyashita M. Multiple primary malignant neoplasms in patients with esophageal cancer. Dis Esophagus 2000; 13: 226-30.

9. Pandha HS, Waxman J. Multiple primary cancers in association with prostate cancer. Cancer Surv 1995; 23: 235-45.

10. Ikeda Y, Saku M, Kawanaka H, Nonaka M, Yoshida K. Features of second primary cancer in patients with gastric cancer. Oncology 2003; 65 (2): 113-7.

11. Ueno M, Muto T, Oya M, Azekura K, Yamaguchi T. Multiple primary cancer: an experience at the Cancer Institute Hospital with special reference to colorectal cancer. Int J Clin Oncol 2003; 8: 162-7.

12. Feliu J. Neoplasias: dos peor que una. Med Clin (Barc) 1994; 102: 136-8.

13. Cosme A, Bujanda L, Ojeda E, Gil I, Barrio J, Torrado J, et al. Carcinoma gástrico asociado a otras neoplasias malignas primarias. Estudio retrospectivo de 25 casos. Rev Clin Esp 2000; 200: 7-11.

14. McGuire V, Whittemore AS, Norris R, Oakley-Girvan I. Survival in epithelial ovarian cancer patients with prior breast cancer. Am J Epidemiol 2000; 152: 528-32.

15. Rubiales AS, Centeno C, Martín Y, Barón FJ, Arranz F, Fra J. Seguimiento del paciente oncológico: ¿Cómo y cuando? An Med Intern (Madrid) 1997; 14: 523-33.

16. Pinol V, Andreu M, Castells A, Paya A, Bessa X, Jover R. Synchronous colorectal neoplasms in patients with colorectal cancer: predisposing individual and familial factors. Dis Colon Rectum 2004; 47: 1192-200.

17. Morita M, Kuwano H, Ohno S, Sugimachi K, Seo Y, Tomoda H, et al. Multiple occurrence of carcinoma in the upper aerodigestive tract associated with esophageal cancer: referente to smoking, drinking and family history. Int J Cancer 1994; 58: 207-10.

18. Slattery ML, Mori M, Gao R, Stat M, Kerber RA. Impact of family history of colon cancer on development of multiple primaries alter diagnosis of colon cancer. Dis Colon Rectum 1995; 38: 1053-8.

19. Johnson N, Lancaster T, Fuller A, Hodgson SV. The prevalence of a family history of cancer in general practice. Fam Pract 1995; 12: 287-9.

20. Dinis-Ribeiro M, Lomba-Viana H, Silva R, Moreira-Dias L, LombaViana R. Associated primary tumors in patients with gastric cancer. $\mathrm{J}$ Clin Gastroenterol 2002; 34: 533-5.

21. Koide N, Adachi W, Koike S, Watanabe H, Yazawa K, Amano J. Synchronous gastric tumours associated with esophageal cancer. A retrospective study of twenty four patients. Am J Gastroenterol 1998; 93: 758-62.

22. Tomoda H, Taketomi A, Baba H, Kohnoe S, Seo Y, Saito T. Multiple primary colorectal and gastric carcinoma in Japan. Oncol Rep 1998; 5: $147-9$.

23. Ritoe SC, Krabbe PF, Jansen MM, Festen J, Joosten FB, Kaanders $\mathrm{JH}$, et al. Screening for second primary lung cancer alter treatment of laryngeal cancer. Laryngoscope 2002; 112: 2002-8.

24. Kumagai Y, Kawano T, Nakajima Y, Nagai K, Inoue H, Nara S, et al. Multiple primary cancers associated with esophageal carcinoma. Surg Today 2001; 31 (10): 872-6.

25. Aydiner A, Karadeniz A, Uygun K, Tas S, Tas F, Disco R, et al. Multiple primary neoplasms at a single institution: differences betwen synchronous and metachronous neoplasms. Am J Clin Oncol 2000; 81: 364-70.

26. Bekdash B, Harris S, Broughton CIM, Caffarey SM, Marks CG. Outcome alter multiple colo-rectal tumours. Br J Surg 1997; 84: 1442-4.

27. Ikeda Y, Saku M, Kawanaka H, Nonaka M, Yoshida K. Features of second primary cancer in patients with gastric cancer. Oncology 2003; 65: 113-7. 